\title{
El teatro femenino de preguerra en España: Elena Fortún y su Teatro para niños (1936)
}

\author{
Pre-war Women's Theatre in Spain: \\ Elena Fortún and her Teatro para niños (1936)
}

\author{
Raquel Molina-Angulo \\ Universitat de Lleida \\ raquel.molina.angulo@didesp.udl.cat \\ ORCID iD: https://orcid.org/0000-0003-2881-9598 \\ Moisés Selfa Sastre \\ Universitat de Lleida \\ mselfa@didesp.udl.cat \\ ORCID iD: https://orcid.org/0000-0001-5394-6471
}

\section{RESUMEN}

Teatro para niños, de Elena Fortún, es el título que aglutina doce comedias de un único acto que esta autora escribió en 1936 y cuya primera edición localizada es de 1942. Con la composición de estas obras, Fortún rompe con los moldes moralizantes del teatro infantil que hasta la fecha venía publicándose en la España de preguerra. A partir de un lenguaje vivo y ágil, del uso de una técnica teatral en la que predominan los juegos y las canciones, y de la desmitificación de los personajes de obras clásicas a través del humor, Fortún se acerca al público infantil con la finalidad de mostrar un espectáculo que lo haga disfrutar y divertirse, huyendo de la intención moralizante que perseguía el teatro infantil de tipo religioso y doctrinal del primer tercio del siglo XX.

Palabras Clave: teatro femenino; Elena Fortún; literatura infantil; Teatro para niños.

\begin{abstract}
Teatro para niños, by Elena Fortún, includes twelve comedies in one act. Teatro para niños was written in 1936 but the first edition was localised in 1942. These theatre plays mark a before and an after in the moralising pre-war theatre in Spain. Fortún uses lively and nimble language and theatre resources like games and songs, and the demystification of classic characters through humour. She appeals to children and young audience with the purpose to amuse the spectators, without following the moralistic inspiration of children's religious and doctrinal theatre of the first third of the $20^{\text {th }}$ century.
\end{abstract}

Key words: Women's theatre; Elena Fortún; Children's literature; Teatro para niños. 


\section{Encarnación Aragoneses Urquijo y Elena Fortún: SEMBLANZA DE UNA METAMORFOSIS VITAL Y NOMINAL}

Encarnación Aragoneses Urquijo (Madrid, 1886-Madrid, 1952), más conocida por el pseudónimo literario de Elena Fortún ${ }^{1}$, es una de las más destacadas escritoras españolas de teatro infantil de preguerra junto a otras plumas como Magda Donato y Concha Méndez (Nieva de la Paz 1993: 113-128). Además de teatro, escribió principalmente narraciones para niños, entre las que destaca la serie Celia (1928-1987)² (Uría 2000: 289), que Martín Gaite calificó como un mito nacido sin vocación de vitrina (Martín Gaite 2004: 8-9).

El tránsito de Encarnación Aragoneses, una mujer de preguerra como tantas otras dedicada mayormente al cuidado de su familia, a Elena Fortún, una escritora independiente y entregada a quehaceres culturales y artísticos de volada, no se entiende sin conocer los entresijos vitales que dibujan la figura de una intelectual con una exquisita sensibilidad por la psicología infantil y el mundo de la cultura y las letras ${ }^{3}$.

De madre vasca y padre segoviano, Encarnación Aragoneses pasó temporadas estivales de su infancia y adolescencia en Abades (Segovia), el pueblo natal de su padre don Leocadio Aragoneses (Dorao 1999: 15, 21). En 1904 aparece en su vida Eusebio de Gorbea Lemmi, un primo segundo suyo, con el que se casó en 1906. Tenía ella 21 años y él $25^{4}$. Tuvieron 2 hijos, Luis y Manuel, a los que Aragoneses se consagró totalmente como madre . El matri-

${ }^{1}$ Elena Fortún adoptó este seudónimo literario de una novela histórica que escribiera su marido Eusebio de Gorbea en 1922: Los mil años de Elena Fortún. Además de este seudónimo utilizó otros como los de Doña Quimera y La Madrina, pero con el tiempo se decantó por el de Elena Fortún (Capdevila-Argüelles 2005: 266).

${ }^{2}$ El último título de la serie, Celia en la revolución, fue publicado en 1987 por Aguilar, 35 años después de la muerte de su autora. Este último título cuenta las vivencias de Celia en la Guerra Civil Española.

${ }^{3}$ No es nuestra intención entrar en detalles en la biografía de Encarnación Aragoneses Urquijo, más tarde Elena Fortún, sino que lo que pretendemos con esta aproximación biográfica es dibujar el perfil humano e intelectual que nos permiten hablar de la metamorfosis vital y nominal de Encarnación Aragoneses Urquijo a Elena Fortún como escritora de Literatura Infantil y de teatro infantil bien reconocida por la crítica contemporánea (Cervera 1982: 162-165; Nieva de la Paz 1993: 260-262; Capdevila-Argüelles 2005). Para adentrarse en detalles en la biografía de Elena Fortún, resulta del todo imprescindible la lectura de Dorao (1999).

${ }^{4}$ Eusebio de Gorbea fue un militar de carrera, si bien su verdadera vocación fue la literatura, que cultivó, sobre todo, con la escritura de textos teatrales (Dorao 1999: 31). Uno de los textos más conocidos de este autor es Los que no perdonan (Premio Fastenrath, 1928), publicado en Madrid por Mundo Libro. Es un drama en cuatro actos estrenado en el teatro Eslava de Madrid, el día 29 de Septiembre de 1928.

${ }^{5}$ Tal fue la dedicación de Encarnación Aragoneses a sus hijos que, al quedar herido uno de ellos, Luis, tras manipular una escopeta junto a su hermano, para que no perdiese el 
monio, debido a los primeros destinos profesionales de Eusebio de Gorbea, se vio obligado a sufrir frecuentes separaciones dada la edad temprana de sus hijos. Encarna permanece en Madrid y frecuenta el parque de El Retiro acompañada de sus pequeños. Allí, se convierte en una apasionada espectadora de los juegos infantiles, de la ingenuidad de los niños, de sus riñas y peleas, que Aragoneses va anotando en unos cuadernos escolares. En estos cuadernillos escolares es donde empieza a gestarse la figura de Elena Fortún (Dorao 1999: 33) y donde se inicia su vocación de escritora, si bien sus primeras publicaciones se harán esperar aún unos años.

1919 es el año en el que Encarnación Aragoneses entra en contacto con personajes relevantes de la cultura madrileña del momento. La familia Gorbea Aragoneses se instala en el número 19 de la calle Ponzano y allí conocen a Santiago Regidor, un catedrático de dibujo y habitual colaborador en la revista Blanco y Negro. Con este y con otras personalidades culturales, entre las que hay que destacar la figura de Matilde $\operatorname{Ras}^{6}$, la familia entabla una estrecha amistad que será duradera y, sobre todo, muy fecunda ${ }^{7}$. Para entonces, Encarnación Aragoneses participa en tertulias organizadas por su marido en las que comienza a conocer a ciertas figuras relevantes de las letras y, en general, de la intelectualidad madrileña de la época (Dorao 1999: 47-48).

En estos mismos años, Encarnación Aragoneses conoce a María Lejárraga de Martínez Sierra, una mujer que marcará profundamente su vida y acelerará su proceso de formación como escritora de Literatura Infantil. Fue precisamente esta quien animaría a Encarna a publicar, a partir del contacto con Torcuato Luca de Tena, el contenido de todos aquellos cuadernillos anotados en El Retiro en Gente Menuda, el suplemento infantil de la Revista Blanco y Negro (Dorao 1999: 81; Uría 2004: 29). Además de Lejárraga de Martínez Sierra, en 1922 Aragoneses forja una intensa amistad con la tinerfeña Mercedes Hernández, esposa del militar Eduardo Díez del Corral, compañero y amigo de su marido (Dorao 1999: 65-70). La amistad con la familia Díez del Corral Hernández fue tal que uno de sus miembros, la niña Florinda Díez Hernández, inspiró el personaje de Celia que Aragoneses creó para la serie de narrativa infantil Celia (1928-1987).

curso y pudiese examinarse por libre, se convirtió en maestra de este preparando a conciencia cada una de las lecciones que debía estudiar (Dorao 1999: 70).

${ }^{6}$ Según Capdevila-Argüelles, ambas autoras «vivieron una singular relación con la palabra escrita y difíciles procesos creativos entre la pujante modernidad de las vanguardias y el feminismo y el peso de la tradición, presente también en sus vidas» (2014: XIII).

7 Santiago Regidor (Madrid, 1866-1942) fue un pintor e ilustrador español formado en la Academia de Bellas Artes de San Fernando de Madrid. Como ilustrador destacó su colaboración en la revista Blanco y Negro, en la que ilustró capítulos de Celia lo que dice (1928), de Elena Fortún. Expuso sus obras en las Exposiciones Nacionales de Bellas Artes y fue distinguido con mención honorífica en las ediciones de 1895 y 1897. 
En noviembre de 1924, Encarnación Aragoneses y su familia regresan de Tenerife a Madrid. Instalada en la capital, frecuenta la Asociación de Mujeres Amigas de los Ciegos, de la que es secretaria y donde estudia Braille. Allí conoce un grupo de mujeres cultas e inteligentes que se reunían en ambientes intelectuales femeninos a los que Aragoneses asiste con gusto. Entra, además, a formar parte de la Sociedad Teosófica de Madrid y estudia Biblioteconomía en el Instituto Internacional de Boston en Madrid. Fue miembro del Lyceum Club $^{8}$, «nido del feminismo español» (Martín Gaite 2004: 81), entre cuyas integrantes se encontraban María de Maeztu, Zenobia Camprubí y María Goyri de Menéndez Pidal.

Es en estos años de intensa actividad intelectual en asociaciones culturales ${ }^{9}$, años también de estudio y en los que situamos sus primeras publicaciones ${ }^{10}$, en los que el proceso de metamorfosis vital y nominal de Encarnación Aragoneses Urquijo, mujer casada y madre (Otero 1999), a Elena Fortún, periodista y reconocida escritora de gran éxito entre el público más joven (García Padrino 1986: 31-54), se consolida definitivamente.

Las primeras colaboraciones firmadas con el pseudónimo de Elena Fortún aparecen en revistas culturales, como por ejemplo La Moda Práctica (Fraga 2013: 157) ${ }^{11}$. Tras estas primeras publicaciones aparecen otras en revistas como Gente Menuda, Pinocho, Crónica, Estampa, Cosmópilis y El Perro, el Ratón y El Gato (García Padrino 2001: 67). Pero sin duda, lo que originó que Elena Fortún se hiciese un hueco entre la nómina de escritoras de preguerra fue el éxito que tuvo con Celia lo que dice (1928), relatos breves que narran pequeños cuadros en los que la niña Celia Gálvez de Montalbán, dotada de una imaginación aguda, vive en un mundo de adultos de los años 20 del siglo pasado a los que no comprende (Franco 2005: 261-267; Caamaño 2007).

El éxito no se hizo esperar y la Editorial Aguilar, en 1932, adquirió los derechos de publicación de los libros de Celia, cuya serie Celia y su Mundo estará formada por once títulos, los seis primeros entresacados de sus publicaciones semanales en Gente Menuda. El primero que se publica es Celia, lo que dice (1928). Después se editan, a medida que Elena Fortún va publicando an-

${ }^{8}$ Una explicación exhaustiva de lo que fue el Lyceum Club y de quiénes integraban esta institución podrá encontrarse en Dorao (1999: 84-89), Hurtado (1999), Fagoaga (2002), Martín Gaite (2004: 18-26), Mangini (2006), Aguilera Sastre (2011), Eiroa (2015: 197-226), González Naranjo (2015: 736-747) y Moreno Lago (2015: 241-252).

9 Martín Gaite califica a Encarnación Aragoneses como una de las socias «más asiduas y hasta viciosas del Lyceum Club» (Martín Gaite 2004: 20).

${ }^{10}$ Este proceso de metamorfosis se afianzó de una vez para siempre con la publicación de 24 de junio 1928, en la revista Blanco y Negro, del primer capítulo de Celia lo que dice.

${ }_{11}$ Anterior a esta reciente publicación, son de consulta imprescindible para conocer la actividad periodística de Elena Fortún los trabajos de Bravo-Guerreira y Maharg-Bravo (2003). 
ticipos en Gente Menuda, otros títulos continuadores de esta serie narrativa infantil: Celia en el colegio (1932), Celia novelista y Celia en el mundo (1934).

Como señala Dorao:

Para la feria del libro de 1934, [Elena Fortún] ya se había comprometido a entregar cuatro libros más: uno de ellos era el último de Celia, Celia y sus amigos, con preciosas ilustraciones de Gori Muñoz, y otro era el primero de Cuchifritín, que iría dedicado a Félix, el niño que lo inspiró; en otro, titulado El bazar de todas las cosas, había reunido todas las labores, construcciones, etc., que llevaba publicadas en revistas, y el cuarto sería uno de comedias infantiles, Teatro para niños (Dorao 1999: 105).

Este libro, que reúne doce comedias en un acto e ilustrado por Dubón, vio la luz en 1936 (Madrid, Aguilar, s.a.) tal y como refleja la publicación especializada en producción libresca Gaceta del libro ${ }^{12}$, pero solo se halló una edición posterior, sin fecha, que se ha podido datar en 1942 (VV. AA. 1996: 221). En 2013 la editorial Renacimiento reeditó esta obra.

Es pues en este momento histórico y vital de intensa actividad creadora en el que debe entenderse esta incursión de Elena Fortún en el mundo del teatro infantil.

\section{SituaCión De LA ESCENA ESPAÑOLA FEMENINA (1918-1936): Elena Fortún y el teatro PARA NIÑOS (1936)}

La situación del teatro infantil escrito por mujeres en el periodo de entreguerras (1918-1936) no se entiende sin «la tradicional división entre un teatro fundamentalmente pedagógico, escolar, centrado en la educación moral y religiosa de los niños, y otro grupo de obras pensadas sobre todo para la diversión y el entretenimiento del público infantil» (Nieva de la Paz 1993: 114). El teatro de tipo tradicional tuvo muy buena acogida en los círculos católicos y en colegios religiosos. Su función era doble: por un lado, el adoctrinamiento moral y religioso de la prole frente a modelos de conducta que eran censurables; por otro, era un tipo de texto destinado a la representación y que ofrecía una ocasión de esparcimiento para los que acudían a las representaciones de este (González Santamera 2003: 2505). Heredero del teatro decimonónico, este tipo de representaciones se escriben mayormente en verso, presenta unos diálogos excesivamente retóricos y el nivel lingüístico del texto era del todo inadecuado para el público al que iba destinado ${ }^{13}$ (Nieva de la Paz 1993: 252). Entre las

12 De la Vega, Elena (Febrero 1936). «El libro infantil: los últimos juguetes de papel y tinta», Gaceta del libro. III, 16, p. 6.

${ }_{13}$ Contra el enfoque excesivamente pedagógico de este tipo de teatro se alzaron voces autorizadas de la época como Jacinto Benavente y, posteriormente, Rafael Alberti y Federi- 
autoras de este teatro moralizante hay que citar a Cristina Aguilá, Pilar Contreras, Micaela de Peñaranda, Matilde Ribot y Carolina de Soto.

Frente a las autoras que buscaron el éxito en representaciones que no iban más allá de mostrar personajes moralizantes y que eran modelos a seguir, algunas escritoras propusieron nuevos caminos para la escritura teatral. Esta búsqueda de nuevos caminos está asociada a la aparición de la nueva mujer moderna en la sociedad española de la época (Regueiro 2015) y que constituye un desafío a los modelos tradicionales de mujer (Vílches de Frutos y Dougherty 1997: 23), en los que el papel de esta estaba relegado a su función vital de esposa y madre. Estos aires de renovación, lógicamente, encontraron su eco en el teatro como en otro tipo de artes (Mangini 2001). Entre las autoras de este tipo de teatro infantil renovador encontramos a Elena Fortún, a Magda Donato - pseudónimo de Carmen Eva Nelken (Branciforte 2012; Nieva de la Paz 1993: 255-260) — y a Concha Méndez (Miró 1992: 439-451; Nieva de la Paz 1993: 262-267; González Santamera 2003: 2519-2520) ${ }^{14}$, tres autoras que, tras la Guerra Civil, tuvieron que exiliarse quedando inacabada la reforma del teatro infantil iniciada en la República ${ }^{15}$.

La figura de Elena Fortún, mucho menos presente en los escenarios teatrales de preguerra que Donato y Méndez (Nieva de la Paz 1993: 260) ${ }^{16}$, representa la transición hacia un nuevo tipo de teatro en el que los temas y el tratamiento que hace de estos permiten hablar de la concepción abierta y novedosa de este género. No se trata de un teatro completamente innovador respecto al que se iba escribiendo y representando en la época, pero sí que observamos elementos novedosos que dan un nuevo aire a la escena española femenina de los años 20 y 30 del siglo pasado. Entre estos elementos destacan el uso de un lenguaje ágil, vivo, muy próximo al lenguaje infantil y desligado de la dicción del verso; la inclusión de elementos populares como dichos y canciones populares; las frecuentes acotaciones que nos dan una idea exacta de cómo es toda la escenografía que rodea la obra teatral; la progresiva desmitificación de los

co García Lorca (Nieva de la Paz 1993: 114-115).

${ }_{14}$ Otras autoras destacadas de este tipo de teatro renovador, pero que dirigieron mayormente sus obras al público adulto, son María de la O Lejárraga, María Teresa Borragán, Halma Angélico — pseudónimo de $\mathrm{M}^{\mathrm{a}}$ Francisca Clar-, Matilda Ras, Angélica del Diablo — pseudónimo de María Palomeras Mallofré-, Carmen Baroja, Isabel Oyarzábal, Pilar de Valderrama, María Luz Morales, Esperanza González, María Teresa León, Irene Falcón y Carlota O’Neill (González Santamera 2003: 2510-2519; 2521-2523).

15 Elena Fortún, junto a Magda Donato, formaron parte como vocales de la Comisión del Teatro de los Niños creada por una Orden del Ministerio de Instrucción Pública, fechada el 6 de enero de 1938 y publicada en la Gaceta de la República el 18 de enero de 1938. Esta Comisión estaba presidida por Benavente (Aznar 1993: 215).

${ }^{16}$ Muchas de sus obras teatrales se estrenaron, como buena parte del teatro infantil del primer tercio del siglo XX, en el marco de fiestas escolares, teatros de arte y salones particulares (Dorao 1999: 96). 
personajes de cuentos infantiles pero sin llegar a despojarlos de su halo fantástico; y la alusión frecuente al recurso del humor con el que los personajes suelen expresarse de un modo ingenuo y sin miedo (Cervera 1982: 162).

Su Teatro para niños, escrito en 1936 y cuya primera edición localizada es de 1942 (Franco 2005: 266), es una publicación que recoge doce obras teatrales en un acto ${ }^{17}$ : Las narices del mago Pirulo ${ }^{18}$; El palacio de la Felicidad ${ }^{19}$; Moñitos $^{20}$; La Bruja Piñonate ${ }^{21}$; Miguelito, posadero ${ }^{22}$; Circo a domicilio ${ }^{23}$; El milagro de San Nicolás ${ }^{24}$; Caperucita Encarnada ${ }^{25}$; La hermosa hilandera y los siete pretendientes ${ }^{26}$; Una aventura de Celia ${ }^{27}$; El manto bisiesto ${ }^{28}$ y Luna Lunera $^{29}$.

Como explica Fortún en el prólogo, el Teatro para niños es una obra dirigida a los niños. De hecho al inicio de dicho prólogo los interpela directamente. Ya en esta presentación de la obra la autora quiere remarcar la intención de erigir en protagonistas a los niños con sus piezas teatrales. Todo está pensado para que el niño sea el centro: el aspecto formal de las piezas teatrales; el decorado y el vestuario dispuesto para su representación, y las ocasiones y los lugares en que estas se representarán. Fortún refleja las intenciones que la han llevado a escribir el Teatro para niños: convertir al niño en el protagonista, fomentar su autonomía y que este no se convierta en la sombra del adulto. Para

${ }^{17}$ El palacio de la felicidad fue la primera pieza que apareció en 1931 en la revista infantil Gente menuda cuyo encabezamiento era «Teatro representable». Posteriormente, publica Las narices del mago Pirulo, Moñitos, Miguelito, posadero, La bruja Piñonate, El milagro de San Nicolás, Circo a domicilio, El manto bisiesto, Caperucita encarnada y Luna, lunera. Estas obras se recogen en el libro de 1942 en el que se añaden Una aventura de Celia y La hermosa hilandera y los siete pretendientes, alcanzando así las doce obras. En el año 1948 vio la luz una segunda edición en Buenos Aires, ciudad donde la editorial Aguilar tenía una filial, pero se omitió Una aventura de Celia, posiblemente por ser la obra más problemática respecto a la censura de la primera edición (Sotomayor 2013).

${ }_{18}$ Estrenada en la Sala Ariel de Madrid por los alumnos de las Escuelas Profesionales de la C.N.T. el 15 de noviembre de 1938 (VV. AA. 1996: 228).

19 No hay referencias de que haya sido estrenada (VV. AA 1996: 226).

20 Representada en las Escuelas de Arte del Sindicato Único del Espectáculo en Madrid por los alumnos de las Escuelas Profesionales de la C.N.T. el 15 de agosto de 1938 (VV. AA 1996: 230).

${ }^{21}$ No hay referencias de que haya sido estrenada (VV. AA 1996: 227).

22 No hay referencias de que haya sido estrenada (VV. AA 1996: 229).

${ }^{23}$ No hay referencias de que haya sido estrenada (VV. AA 1996: 224).

${ }^{24}$ No hay referencias de que haya sido estrenada (VV. AA 1996: 225).

${ }^{25}$ No hay referencias de que haya sido estrenada (VV. AA 1996: 223).

${ }^{26}$ No hay referencias de que haya sido estrenada (VV. AA 1996: 228).

27 No hay referencias de que haya sido estrenada (VV. AA 1996: 231).

${ }^{28}$ No hay referencias de que haya sido estrenada (VV. AA 1996: 224).

${ }_{29}$ Estrenada en el Teatro de la Comedia de Madrid, el 16 de febrero de 1930 (VV. AA 1996: 220; Vilches de Frutos y Dougherty 1997: 486). 
ello, les facilita la propuesta de un vestuario sencillo que pueden encontrar o elaborar ellos mismos:

Algunas [de las doce comedias] podréis hacerlas en casa las tardes en que la lluvia o el frío no permitan salir, y sin auxilio de mayores, con algunas telas por fondo, los muebles de vuestro cuarto, los vestidos viejos de mamá y algunos recortes graciosos de papel de seda (Fortún 2013: 9).

Además tiene en cuenta la duración de las obras —un acto- según el tiempo en el que la atención de los niños puede fijarse. Pese a la intención adoctrinadora de algunas de las obras recogidas en Teatro para niños, en otras, Fortún insinúa cierta transgresión:

Otras comedias podrán ser útiles en las fiestas del Colegio. Habéis visto a los profesores y al director, terriblemente preocupados algunas veces, revolviendo libros viejos y revistas modernas para encontrar una comedia menos ñoña que las conocidas y sin esa atroz moraleja, casi siempre estúpida, dulzona y empalagosa (Fortún 2013: 9)

La autora es consciente de que para atraer la atención de los niños a sus creaciones los ha de tratar como iguales y otorgarles confianza, mostrarles que sabe que tienen criterio. Por eso les expresa que si lo desean pueden cambiar el orden de las obras presentadas en Teatro para niños puesto que afirma que dicha clasificación es algo caprichosa.

El texto inicial sigue las características de los exordios: la modestia y la prudencia están presentes al final del prólogo en el que vuelve a remarcar que ha escrito las obras pensando en los niños: «contando con que habéis de corregirme, en esto y en todo, y colaborar conmigo como buenos y antiguos amigos que somos, entrego en vuestras amables manos esta docena de comedias que he escrito pensando en vosotros» (Fortún 2013: 10).

El hecho de anteponer el niño al adulto, la complicidad que busca con el público infantil y el deseo de querer alejarse de obras caducas, de moraleja atroz, estúpida, dulzona y empalagosa — como ella misma las denomina-, marca el inicio de la transición hacia un nuevo tipo de teatro. La intención de Fortún es postular una relación de igual a igual con su público, alejarse de la relación jerárquica vertical, en la que el adulto buscaba el adoctrinamiento del niño a través de piezas teatrales de marcado carácter moralizador.

\section{TÉCNICA TEATRAL Y LENGUAJE EN TEATRO PARA NIÑOS (1936)}

Para convertir al niño en el eje vertebrador de su obra, Fortún no solo escribe las obras teatrales pensando en los niños como receptores, sino que además serán ellos los que las representarán. Por este motivo, se sirve de un len- 
guaje ágil, vivo, muy próximo al lenguaje infantil y desligado de la dicción del verso. Esta será una de las características que, como indica Cervera (1982: 162), marcarán la transición hacia una nueva manera de escribir teatro. De las doce obras que conforman Teatro para niños, nueve de ellas ${ }^{30}$ están escritas en prosa y tres ${ }^{31}$ en verso. Estas últimas, tal y como remarca Fortún en el prólogo, están escritas «en sencillos pareados» (Fortún 2013: 9). El hecho de desligarse de la dicción del verso en la mayoría de las obras y de escribir otras en versos sencillos dará lugar a que los niños que representan las obras memoricen con mayor facilidad el texto que tengan que verbalizar. Asimismo, los niños que presencien las obras como público comprenderán de una manera más sencilla y amena el argumento de la pieza teatral. Otro de los elementos facilitadores para la memorización y la comprensión de los textos teatrales es la inclusión de elementos populares como dichos y canciones. Además de cumplir las funciones anteriormente remarcadas, esta técnica teatral aportará un elemento socializador tanto para los niños-actores y actrices que representen la obra como para el público que la presencie, puesto que producirá un sentimiento de pertenencia e identificación a una misma comunidad. Así, por ejemplo, podemos encontrar juegos lingüísticos y literarios que desafían el ingenio y la imaginación como las adivinanzas ${ }^{32}$, que además buscan captar una mayor atención de los espectadores. Un ejemplo de canción popular sería la «La buena viejecita», cantada en el juego que lleva el mismo nombre y que unos niños entonan al principio de la obra Moñitos:

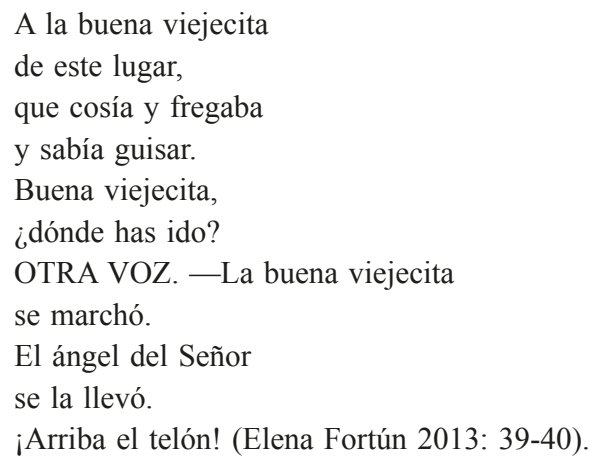

${ }^{30}$ Las narices del mago Pirulo; El palacio de la felicidad; Moñitos; La bruja Piñonate; Miguelito, posadero; Circo a domicilio; Caperucita encarnada; Una aventura de Celia; Luna lunera.

${ }^{31}$ El milagro de San Nicolás; La hermosa hilandera y los siete pretendientes; El manto bisiesto.

32 Hada amarilla. — ¿Qué cosa es que mientras más se mira menos se ve? [...] / Gnomo $1^{\circ}$. - Como no sea la oscuridad... / Hada ex amarilla. — ¡Eso es! ¿Y una cosa que lleva la camisa por dentro y la carne fuera?/Gnomo $3^{\circ}$. — ¡Yo lo sé, yo lo sé! ¡La vela! (Elena Fortún 2013: 31-32). 
En este juego escénico infantil, de diferentes variantes (Medina Padilla 1987: 72-73), se coloca en el centro la «viejita» que es rodeada por el coro con el que dialoga. En cada una de las estrofas un niño distinto interviene en la conversación.

La canción y el juego también están presentes en la obra Luna lunera. En este caso se trata del popular juego de azar echar a chinas $^{33}$, en el que dos brujitos compiten por ver quién acompaña a la bruja a Palacio:

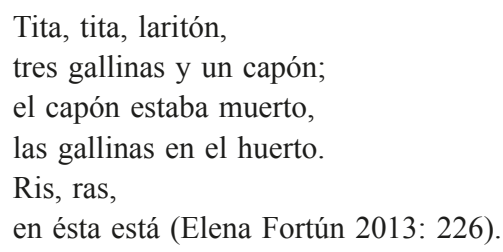

En la obra La bruja piñonate encontramos otro ejemplo de canción al final de la obra. Se trata de un canto con una rima sencilla y una letra poco compleja, con algunas creaciones de palabras y con cierto tono macabra, puesto que en ella algunos personajes se regocijan de la muerte de la bruja:

La bruja ya se ha muerto, carabí

la llevan a enterrar, carabí, urí, urá.

Elisá, Elisá de Mambrú.

La caja era de plata, carabí,

con tapa de cristal; carabí, urí, urá,

Elisá, Elisá de Mambrú.

Encima de la tapa, carabí,

dos pajaritos van, carabí, urí, urá.

Elisá, Elisá de Mambrú (Elena Fortún 2013: 64).

Uno de los elementos propios de la tradición oral presente en este volumen de teatro de Elena Fortún es la nana. Una de las nanas más interesantes que ofrece Fortún es la que aparece justo antes de que se cierre el telón en la comedia de Navidad Miguelito, posadero. Esta nana, como colofón final de la obra con motivos navideños, remarca el lazo con la tradición oral que mantiene Fortún, pero a la vez es una muestra del toque de comicidad e ironía que aporta con sus obras al cambiar el posesivo mi por la conjunción copulativa negativa $n i$ :

A la nanininananá, nanita ea.

Ni Jesús tiene sueño, ¡bendito sea! (Elena Fortún 2013: 78).

33 «Ris, ras, / en ésta está» (Elena Fortún 2013: 226). 
Otro de los aspectos más destacables de la técnica teatral de Elena Fortún son las frecuentes acotaciones que nos dan una idea exacta de cómo es toda la escenografía que rodea la obra teatral, ya que facilitan que los niños y niñas representen las piezas teatrales sin demasiada dificultad. En Teatro para niños las acotaciones siguen un esquema fijo: primeramente, aparece el listado de personajes; en la mitad de las obras ${ }^{34}$ aparece únicamente el nombre de los personajes, pero en la otra mitad ${ }^{35}$ encontramos también una breve pero precisa explicación de cómo se han de caracterizar dichos personajes. Además se explica de una manera muy didáctica los recursos que pueden seguir los niños para encontrar el vestuario de los personajes. A continuación, al comienzo de cada acto y escena encontramos las acotaciones más extensas en las que se describe el decorado donde se llevará a cabo la acción. Por último, intercaladas en el texto, aparecen diversas acotaciones y referencias o alusiones deícticas para indicar la escenografía, el movimiento de los personajes, su expresión facial y sus emociones.

En todas las acotaciones predomina la objetividad. No se caracterizan por su valor literario, su funcionalidad es de carácter pragmático, ya que han sido escritas para facilitar la labor de los niños. Para ello la autora se sirve de diferentes recursos lingüísticos como las comparaciones ${ }^{36}$. Asimismo, encontramos acotaciones que hacen referencia a hitos de la literatura universal, como el Fausto de Goethe, para explicar cómo se ha de caracterizar al niño que represente el personaje del diablo en La hermosa hilandera y Los siete pretendientes: «El niño que haga el papel de Diablo debe ser el más alto y delgado de la Compañía. El traje será lo más parecido posible al de Mefisto, de "Fausto"» (Elena Fortún 2013: 136).

La manera de escribir acotaciones de Elena Fortún es una muestra más del cambio de paradigma del teatro que aporta la autora. La minuciosidad por la descripción y el didactismo utilizado rigen la idiosincrasia de las acotaciones de la dramaturga infantil. Como ya se ha dicho anteriormente, las acotaciones no se caracterizan por su valor literario, si bien sí que se pueden encontrar en ellas detalles simbólicos que a su vez muestran la importancia que la autora otorga al valor estético. Para ello, Fortún se sirve de recursos sencillos y cotidianos pero de gran efectividad ${ }^{37}$. La minuciosidad por los aspectos visuales de las representaciones se refleja además en las características físicas de los niños

${ }^{34}$ El palacio de la felicidad; Moñitos; Circo a domicilio; El milagro de San Nicolás; La hermosa hilandera y los siete pretendientes; El manto bisiesto.

${ }^{35}$ Las narices del mago Pirulo; La bruja Piñonante; Miguelito, posadero; Caperucita encarnada; Una aventura de Celia; Luna, lunera (en esta comedia solo aparece la caracterización de dos de los personajes: «La luna» y «Galopón»).

36 «Todo él brilla a la luz de millares de luces como las casitas cubiertas de escarcha de los Nacimientos» (Elena Fortún 2013: 31); «la hilandera será una niña de once a trece años, que sea muy bonita, y llevará las mejillas pintadas con chapas rojas como una muñeca» (Elena Fortún 2013: 129).

37 «San Nicolás, en medio, y los niños rodeándole, forman un grupo que debe iluminarse con una bombilla de luz potente oculta hasta este momento» (Elena Fortún 2013: 110). 
y niñas que representan la obra y que la autora indica en las acotaciones para que las obras sean lo más verosímiles posibles ${ }^{38}$. Esta verosimilitud es a la vez reforzada por el simbolismo propio del teatro y el pacto ficcional que se establece entre actores y actrices y espectadores. Uno de los aspectos más evidentes que ejemplifican el pacto ficcional es el hecho de fingir que un niño es un adulto. Para ello, Elena Fortún utiliza diversos recursos como, por ejemplo, los que encontramos en la obra El milagro de San Nicolás: «El carnicero debe ser un niño gordo, con mandil blanco y barba negrísima, que puede hacerse esponjando un buen trozo de crepé» (Fortún 2013: 101). O el siguiente ejemplo: «por fin, aparta las manos de la cara y se ve que tiene la barba enteramente blanca (Esta barba puede hacerse de algodón en rama)» (Fortún 2013: 105).

En lo que se refiere al lenguaje empleado en Teatro para niños, este se caracteriza por ser muy próximo al de los niños. Así, por ejemplo, predomina la agilidad verbal. Con la inclusión de elementos populares como dichos y canciones populares, Fortún consigue empatizar con el público infantil del momento puesto que muchas de las canciones que aparecen en sus obras son las que utilizan los niños en sus juegos (Cervera 1982: 162-165 y Nieva 1993: 260-262), todo ello para consolidar el objetivo de hacer de los niños los protagonistas de su obra:

\begin{abstract}
El humor, la agilidad de los diálogos, la abundante presencia de canciones, juegos infantiles y dichos populares, el movimiento de personajes y la atinada funcionalidad de las acotaciones son rasgos característicos de este nuevo teatro que puede ser leído, visto o representado por niños. Es muy significativo el hecho de que Elena Fortún, en la edición de su Teatro para niños, advierta que algunas de las piezas puedan utilizarse para representar en la escuela: aunque estas reflexiones no constan en la edición en Gente menuda, no cabe duda, incluso aquí, de que fueron escritas pensando en los intereses y gustos de los niños reales, considerados como seres autónomos y no sólo como «sujetos educables» (VV.AA. 2008: 100).
\end{abstract}

En segundo lugar, las frecuentes y precisas acotaciones facilitan a los más pequeños a representar las obras con la ayuda mínima de los adultos o incluso sin ella. Además facilita a los espectadores la comprensión de las obras y a los lectores les proporciona una idea exacta de cómo es toda la escenografía que rodea la obra teatral.

\title{
4. EL TRATAMIENTO DE LOS PERSONAJES Y DEL HUMOR EN TEATRO PARA NIÑOS (1936)
}

Cervera (1982: 162) destaca dos elementos como novedosos en la dramaturgia de Elena Fortún respecto al teatro que se había escrito y representado

38 «pero es indispensable que sea el niño más alto de todos los actores que representan esta comedia. La MAMÁ, que también debe ser una niña alta [...]» (Elena Fortún 2013: 83); «San Nicolás será un niño rubio» (Elena Fortún, 2013: 109). 
hasta la fecha: la progresiva desmitificación de los personajes de cuentos infantiles pero sin llegar a despojarlos de su halo fantástico y la alusión frecuente al recurso del humor con el que los personajes suelen expresarse de un modo ingenuo y sin miedo.

En Teatro para niños encontramos reminiscencias de la tradición como adaptaciones de cuentos y obras ambientadas en fiestas tradicionales y en motivos sacros, pero a la vez descubrimos ese aire nuevo que marca la transición a un nuevo teatro con el tratamiento distinto de estos motivos religiosos y con el humor como eje principal de este cambio. Son tres las obras donde especialmente se puede observar este péndulo oscilante entre tradición y modernidad: Miguelito, posadero, que es una comedia ambientada en la Navidad; El milagro de San Nicolás, un entremés guiñolesco con motivos sacros y Caperucita encarnada, comedia en un acto que es la adaptación escénica del cuento popular.

Esta progresiva desmitificación de los personajes de cuentos infantiles se lleva a cabo de una forma muy similar a como se desmitifican los personajes del ámbito sacro. En algunas de las obras de Fortún los personajes sacros aparecen con poca solemnidad. Así, por ejemplo, en Miguelito, posadero, la Virgen María y San José no aparecen de manera física en la escena, sino que están presentes en la obra a través de la voz de Miguelito que avisa a su abuela de su llegada pidiendo asilo. La abuela, desconfiada porque anteriormente un hombre ya había engañado a su nieto con el fin de robarle dinero, le ordena que no les abra la puerta. Otro personaje bíblico que sí aparece físicamente en la obra es el ángel Gabriel. Este personaje se muestra cercano y terrenal pidiendo ayuda a Miguel porque está herido por algo tan banal como el hecho de haber olvidado que tenía alas: «Estoy herido, Miguel. Se me ha roto un ala... Me había sentado en un árbol verde, sobre los tres pastores que comen migas..., se me olvidó que tenía alas y me rompí ésta...» (Elena Fortún 2013: 74).

Miguelito posadero ofrece una doble moraleja que agudiza el ingenio del espectador y del lector, puesto que huye de la simple moraleja clásica y dogmática y se sirve de las ambivalencias y contradicciones que presenta la condición humana. La doble moraleja plantea, por una parte, la clásica advertencia que siempre se les ha inculcado a los niños en fábulas y cuentos: no hay que fiarse demasiado de los desconocidos, ya que el protagonista es engañado al principio de la trama por un desconocido que le acaba robando después de ganarse su confianza. Por otra parte, siendo también esta una manera de regalar al espectador un desenlace sorpresivo, la otra cara de esta moraleja aboga por no ser demasiado desconfiados, puesto que Miguel y su abuela, por no dar posada a la Virgen María y San José, acaban teniendo parte de culpa de que el niño Jesús nazca en un establo. Con esta moraleja de doble cara, que también aparece en otras obras, Fortún huye del maniqueísmo presente hasta el momento en el teatro infantil escolar de carácter más doctrinal. La dramaturga parece confiar nuevamente en su público infantil: confía en la capacidad de los niños 
y en su voluntad de entender que el punto medio, tan alabado en las teorías aristotélicas, es la solución al problema planteado en la trama de la obra teatral.

El milagro de San Nicolás, como Miguelito, posadero, es una pieza con motivos sacros, en la cual aparece un santo - San Nicolás - y se presenta de una manera muy cercana. El milagro provocará la resurrección de los tres niños que el carnicero había hecho picadillo. Este hecho sobrenatural se presenta de una manera muy sencilla, siendo esta una muestra de la desmitificación que Fortún emplea con sus personajes, incluso con los personajes bíblicos:

SAN NICOLÁS. - En nombre del Padre, yo te resucito.

NIÑO $1^{\circ}$. - (Sale de la artesa desperezándose.)

¿Me llaman? ¡Despierto! ¡Que buen sueñecito!

SAN NICOLÁS le ayuda a salir y el NIÑO se agarra a su manto.

SAN NICOLÁS. - (Poniendo los dedos en el borde de la artesa.)

Despierta tú ahora, mi Niño querido.

NIÑO $2^{\circ}$. - (Sacando la cabeza de la artesa.)

¿Es ya de mañana? ¡Qué bien he dormido!

SAN NICOLÁS le ayuda a salir y el NIÑO se coge del otro lado de su manto.

SAN NICOLÁS. - (Pone un dedo en el borde de la artesa.)

Es tu vez, muchacho, y acabe esta historia.

¡Despierta!

NIÑO $3^{\circ}$. - iSoñaba que estaba en la Gloria! (Elena Fortún 2013: 110).

Caperucita encarnada es una adaptación del cuento Caperucita Roja recogido por primera vez por Charles Perrault y versionado por distintos autores ${ }^{39}$. En el título de la obra teatral advertimos que Fortún ha optado por el adjetivo encarnada en vez de roja. El color rojo/encarnado con connotaciones ideológicas puede llevarnos a la cuestión de por qué ha utilizado un adjetivo y no otro. Aunque en los años recientes se ha popularizado el adjetivo roja para el título de dicho cuento, años atrás el adjetivo más utilizado era encarnada. En el siglo XIX la traducción habitual era «Caperucilla/Caperuchita/Caperucita Encarnada», exceptuando a traductores como Baró 1883 que prefieren la traducción «Caperucita Roja» (Martens, 2016: 204).

Caperucita encarnada de Elena Fortún es una adaptación híbrida entre la versión recogida por Perrault y la de los Hermanos Grimm. Como en la versión de Perrault, la abuela es comida por el lobo y, a diferencia de la versión de los Hermanos Grimm, no aparece ningún cazador que logre sacar a la abuela sana y salva de la panza del lobo. Pero a diferencia de la adaptación de Perrault, Caperucita no es comida por el lobo. Por lo tanto se conserva en parte el final feliz de los Hermanos Grimm. El hecho de que Caperucita no sea devorada por

39 Entre las versiones más conocidas, se encuentra sin duda la de los Hermanos Grimm que data de 1812 . 
el lobo lleva implícita una carga de simbolismo: el lobo, al ver reflejada la imagen de Caperucita en un espejo, se acaba comiendo el espejo pensando que se come a Caperucita y, en consecuencia, muere. No todo es lo que parece y los matices vuelven a estar presentes en la obra de la dramaturga madrileña que, con el tratamiento de los personajes, el humor y la ironía, consigue aportar cierta transgresión al mensaje del cuento original. La moraleja sigue siendo prácticamente la misma: la advertencia a los niños para que no hablen con desconocidos y, como en el cuento tradicional, Fortún hace hincapié en la culpa de Caperucita por hablar más de la cuenta, pero lo hace aportando a la situación una dosis de humor:

CAPERUCITA. —iMadre! ¡Aquí estoy! El lobo se tragó un espejo porque en él vio mi imagen...

MAMÁ. -Pero, ¿tú qué hiciste, desgraciada?

EL LEÑADOR. - (Saliendo.) Hablar, señora, hablar más que un sacamuelas...

(Elena Fortún 2013: 123).

Si bien es cierto que en la obra teatral no se exime de culpa y de ingenuidad a Caperucita por hablar más de la cuenta con desconocidos y por entretenerse demasiado por el camino, la Caperucita de Fortún se muestra mucho más contestataria y rebelde que la tradicional en su enfrentamiento con el lobo:

CAPERUCITA. — ¡Tú sí que eres tonto!

LOBO. - Cuando me vea tu abuela no dirá eso y me dará torta...

CAPERUCITA. - ¡Huy, qué tonto eres! Te creerás tú que mi abuelita te va a dejar entrar... Cuando yo llegue le diré que atranque bien la puerta

(Elena Fortún 2013:120).

Moñitos y Una aventura de Celia son dos obras en las que las niñas se erigen como protagonistas. Las protagonistas femeninas son muy diferentes la una de la otra. Mientras que Moñitos es el prototipo de niña buena que se desenvuelve con destreza y máxima pulcritud en las tareas del hogar, Celia es una niña rebelde que se muestra transgresora y traviesa con los adultos que la rodean.

En Moñitos encontramos elementos fantásticos: los animales hablan y su comportamiento es parecido al de los humanos. Pero a la vez nos encontramos con la progresiva desmitificación de los personajes de cuentos infantiles de la que hablaba Cervera (1982: 162), puesto que los animales se muestran poco hábiles en las tareas domésticas, no saben hacer nada y se sienten desprotegidos si no hay ningún humano que les ayude. Además de elementos fantásticos encontramos otras alusiones a los cuentos tradicionales, como la casita en el bosque que descubre la protagonista mientras recuerda que en todos los bosques hay una casita, produciéndose así un momento metaliterario: «iHuy, una casita! Es la casita del bosque... Porque en todos los bosques hay una casita. Unas 
veces dentro de la casita vive un viejo; otras, vive un ogro; otras, un hada; otras..., los ladrones...» (Fortún 2013: 43).

El humor está muy presente en la obra, sobre todo en la imagen cómica de los animales intentando realizar las tareas del hogar con resultados desastrosos, y en la figura del grillo con sus canciones burlonas.

El personaje de Moñitos se asemeja a otros personajes femeninos del imaginario tradicional como Blancanieves. Se trata de jóvenes que se encuentran solas y sin hogar — en el caso de Moñitos, como ella misma dice, «no tiene padre ni madre ni perrito que le ladre» (Elena Fortún 2013: 43) — y que acaban siendo acogidas en una casa a cambio de realizar las tareas del hogar y cuidar de sus inquilinos: los siete enanitos en el caso de Blancanieves, y del gallito, la mona y el gato en el caso de Moñitos. Se trata de una aparente simbiosis que realza el tradicional concepto de la importancia de saber desenvolverse a la perfección en las tareas domésticas.

Como sostiene Nieva de la $\mathrm{Paz}^{40}$, Una aventura de Celia es una de las obras más destacadas de este volumen de teatro infantil por la relevancia del personaje de Celia. A este respecto Carmen Martín Gaite señala que «el 24 de junio de 1928, aparecía impreso por primera vez el nombre de Celia en un cuentecito breve firmado por Luisa que se titulaba Celia dice a su madre, y escrito totalmente en forma de diálogo» (2004: 33). Esta obra, de la misma manera que ocurrió con el prólogo, tuvo problemas con la censura, como afirma Sotomayor: se consideraba que tenía «frases desacertadas e irrespetuosas», «que no son buen ejemplo para los niños» (Sotomayor 2005: 409).

Es significativo que esta primera aparición de Celia esté escrita totalmente de manera dialogada y que en los sucesivos cuentos protagonizados por Celia el diálogo tenga un papel primordial. Este podría ser un indicio del deseo de Fortún de teatralizar las aventuras de Celia y que hizo realidad en la obra teatral a la que hemos hecho referencia.

El personaje de Celia muestra con su mezcla de ingenuidad, sinceridad y rebeldía el contraste entre la sociedad burguesa acomodada y la obrera. Saca a la luz estas diferencias de una manera crítica, sirviéndose del humor y la ironía. La ostentosa merienda que ofrece la abuelita de María Luisa, una amiga de Celia, muestra el deseo de aparentar, de presumir, de pertenecer a la sociedad bien estante. En cambio, Celia es contestona, sincera y rebelde, algo que escandalizará a la abuelita de María Luisa y a sus invitados. Las situaciones y el tratamiento de los personajes de esta obra van acompañados de una fuerte carga humorística y una ironía que recuerda a la del teatro del absurdo, tal como podemos ver en la ingenuidad de la niña María Luisa que

40 «Aguilar publicó en 1948 otra edición de la citada antología en la que no aparece recogida La aventura de Celia, tal vez la obra más conseguida. Llena de encanto y humor, presenta las mil y una travesuras de una Celia en vacaciones enfrentándose sin temor a los insufribles adultos que la rodean» (Pilar Nieva de la Paz 1993: 121). 
confunde el sentido literal de expresiones y dichos con el figurado, dando lugar a cómicos juegos lingüísticos. Según Martín Gaite (2004: 41) el hecho de aplicar la lógica infantil para desmontar las frases hechas es una de las modalidades estilísticas de Elena Fortún que la vincula con el código de lo surrealista. Un ejemplo de esta técnica lo encontramos en este diálogo entre nieta y abuela:

ABUELITA. - ¡Mira qué cuadro!

MARÍA LUISA. - (Mirando a las paredes.) No lo veo. ¿Dónde está?

ABUELITA. — ¿Dónde miras, tonta? Mira a la mesa (Elena Fortún 2013: 144).

Este recurso cómico también está presente en el siguiente diálogo entre Romualdo, uno de los invitados a la casa de la abuela de María Luisa, y la niña:

ROMUALDO. - Deja a esa niña. Las manzanas podridas pican a las sanas.

MARÍA LUISA. - ¡Qué tonto! ¿De qué manzana habla, si aún no han madurado las de la huerta? (Elena Fortún 2013: 152).

Otro ejemplo de ironía fina y más difícil de captar por el público infantil son estas palabras de Romualdo, uno de los invitados a casa de la abuela de María Luisa: «Yo soy muy bueno, no lo puedo remediar. En cuanto veo un chico mal educado le molería a palos, aunque no me lo agradeciera...Soy así...» (Fortún 2013: 151).

Como se puede apreciar en esta obra teatral y en todo el ciclo de Celia, la actitud de Celia tiene un trasfondo más allá de amenizar y divertir con sus ocurrencias a lectores y espectadores, y esto se refleja en el hecho de hacer tambalear los dogmas de una sociedad hipócrita y pasiva. La actitud de Celia es reprehendida por algunos adultos, representantes sobre todo de la sociedad más clasista y tradicionalista, pero también es defendida por otros, como por ejemplo su tío Rodrigo que acaba dando la razón a su sobrina al final de la obra y por la que da la cara ante el poder eclesiástico representado por las monjas que rigen el colegio de Celia.

En Una aventura de Celia se pueden apreciar rasgos característicos de la escritura de Elena Fortún, como la aparición de elementos fantásticos - animales personificados - mezclados con la cotidianeidad, si bien en esta obra teatral encontramos una técnica inversa: la explicación lógica de hechos fantásticos, tal como puede apreciarse en una conversación entre Celia y la cigüeña:

CIGÜEÑA. — ¡Eres una niña!

CELIA. - ¡Naturalmente! ¿Qué querías que fuera?

CIGÜEÑA. - Nunca las personas hablan con las cigüeñas.

CELIA. - ¿No? Lo creo, porque las personas son medio tontas.

CIGÜEÑA. - Por eso nosotras no hablamos nunca... 
CELIA. - iQué aburrido debe ser eso! No sé cómo no se os olvida hablar.

CIGÜEÑA. -Algunas lo han olvidado... (Fortún 2013: 153).

Siguiendo con la temática del protagonismo infantil y de las visitas de los niños a casa de sus amigos, encontramos la obra Circo a domicilio, en la que el humor se basa sobre todo en los enredos que se producen. Un elemento importante en lo que a comicidad se refiere es el doctor con sus intervenciones irónicas e hilarantes y la expresión «yo no respondo» utilizada casi al final de cada frase que emite: «Sí, señora muy malito. Si sigue así estirará la pata. Si estira las dos, síntoma de crecimiento...; si estira una primero y luego otra..., no respondo» (Fortún, 2013: 85).

Los ejes temáticos principales de la obra son la amistad y el metateatro, siendo la representación del circo que le ofrecen sus amigos a Fiquito lo que sanará al niño.

En este compendio teatral destinado a los niños destacan también las obras teatrales que siguen la tradición de reyes, magos, brujas, hadas y personajes fabulísticos. Todo ello mezclado con el peculiar tratamiento humorístico que desprende la pluma de Fortún. Dentro de este grupo temático se pueden distinguir obras como Las narices del mago Pirulo, en la que los rasgos de la comedia de enredos y el teatro del absurdo están muy presentes. Ejemplo de ello es el lenguaje cómico y los diálogos hilarantes y surrealistas de los distintos personajes que aparecen en la obra:

SOLDADITO. — ¡Tararí! ¡Píiiiii!... ¡Píiiii!... Perdone usted, pero estoy acostumbrado a los toques de corneta y no puedo hablar seguido si no los oigo...

ROENUECES. - Bueno, pues explíquese usted, y entretanto yo tocaré la corneta. ¡Tararíiiiii! ¡Tararíiiii!... (Elena Fortún 2013: 17).

El final de la obra adquiere un valor significativo a nivel sentimental que percibirán mejor los adultos que los niños:

El SOLDADITO toca la corneta: "Tararí, piii, píiii»; el MAGo baila, recogiéndose las faldas, y ROENUECES está muy contento.

BISMUTO. - (Entrando.) ¡Formalidad, formalidad, formalidad! Precisamente cuando se es feliz importa conservar la ecuanimidad y el ánimo sereno. Mucho vale una nariz, pero más vale el juicio...

TODOS. — ¡Fuera el doctor Bismuto, fueraaaaa! (Fortún 2013: 22).

El palacio de la felicidad, estructurado en un acto y dos cuadros, es una de las obras más breves de Teatro para niños. En ella están comprimidas ideas y sensibilidades con las que, como sucede también en Las narices del mago Pirulo, los adultos se sentirán más identificados que los niños: sentimientos humanos como el egoísmo, el afán por aparentar y hacer las cosas por los demás teniendo una existencia vicaria, el deseo de rebelarse, de 
querer ir a contracorriente ${ }^{41} \mathrm{y}$ el humor que no es del todo políticamente correcto $^{42}$.

La bruja piñonate y Luna lunera son las dos obras de Teatro para niños en las que aparece uno de los personajes fantásticos más recurrentes en la literatura infantil: la bruja. En La bruja piñonate encontramos un parecido notable con el cuento Hansel y Gretel y con otros tantos del imaginario colectivo, en los que la bruja alimenta a una niña con el fin de hacerla engordar para comérsela posteriormente. Otra de las similitudes con el cuento recogido por los hermanos Grimm es el lugar donde vivía la bruja: «en el bosque en su casita de turrón» (Elena Fortún 2013: 58). Como hemos visto anteriormente, el hecho de beber de fuentes literarias anteriores y a la vez mezclarlas con estos recursos estilísticos propios, transgresores y humorísticos, es una seña de identidad del teatro Elena Fortún. En el final de La bruja Piñonate encontramos un giro argumental al cuento El príncipe rana, también recopilado por los hermanos Grimm. En este caso la bruja se convierte en una rana.

La ironía ${ }^{43}$, la metalengua ${ }^{44}$ y los juegos de malentendidos lingüísticos ${ }^{45}$ son clave en esta obra como recurso cómico y para crear conciencia lingüística.

Luna lunera, estrenada antes de la guerra, con diecinueve personajes, es la obra con el número de personajes más elevado y una de las más extensas. Según Cervera este hecho resulta algo negativo para la puesta en escena:

A pesar de que la autora la haya escrito para muñecos de guiñol parece haber acumulado demasiados personajes que indudablemente dificultarán este tipo de puesta en escena. Por la misma razón puede quedar la acción un tanto dispersa al montarla actores o niños (Cervera 1982: 165).

En esta pieza teatral encontramos elementos fantásticos y personajes que siguen la tradición de brujas, reyes y príncipes, presentados de una manera ma-

41 «HADA ROSA. —Vamos. Poneos en fila de dos en dos... / GNOMO $3^{\circ}$. — ¿De dos en dos? ¿Y por qué no en fila india? / GNOMO $1^{\circ}$. - Yo no quiero ir en fila... Vayamos andando sencillamente, que ya llegaremos».

${ }^{42}$ «HADA VIOLETA. — ¡Felicidad absoluta! ¡Felicidad única! ¡Divina felicidad! / GNOMO $1^{\circ}$. —iVamos, anda!... ¡So cursi!... / HADA ROSA. —No le hagas caso. Hace muchos años que vivía en la bodega de una taberna..., y todo se pega menos la hermosura. / GNOMO 1 $1^{\circ}$ - — ¿Y tú, dónde has vivido, princesa? Detrás del dosel de una escuela, y te has hecho tan indigesta como la maestrita...» (Elena Fortún 2013: 28).

43 «Pues no hay nada, a no ser que haya algo» (Elena Fortún 2013: 59).

44 «Las faltas de respeto son casi tan grandes como las de ortografía... Si se pone sin acento una palabra que lo lleva...» (Elena Fortún 2013: 58).

45 «TONTILINDÓN. -Es una buena mujer... / MARIBEL. - No, papá, al revés... / TONTILINDÓN. - Una mujer buena... Sí, el sentido varía cuando el adjetivo sigue al nombre en lugar de precederle. / MARIBEL. - (Desesperada.) ¡No me haces caso! Te digo que Piñonate era una bruja...» (Elena Fortún 2013: 66). 
niquea. El argumento se desarrollará en torno a las artimañas de la bruja por usurpar el trono. Finalmente, será vencida por el príncipe con la ayuda de la Luna.

En el tratamiento del personaje de la bruja, se puede observar alguna frase truculenta que confiere un cierto dramatismo a la situación representada, un rasgo que encontramos de manera similar en la trama de Miguelito, posadero: «¡El Príncipe Pepito no aparecerá nunca! He mandado buscarle a dos ladrones, que le matarán y me traerán su corazón para que me lo coma con salsa de tomate...» (Elena Fortún 2013: 227).

La hermosa hilandera y los siete pretendientes, junto con El manto bisiesto, conforman un binomio que sigue la tradición de los pretendientes que han de superar pruebas u obstáculos para conseguir a su amado o amada. En la concepción más tradicionalista es normalmente el hombre quien ha de superar estas pruebas para conquistar a su amada, convirtiéndose la mujer en una especie de trofeo.

La hermosa hilandera y los siete pretendientes, basada en un cuento de Matilde $\operatorname{Ras}^{46}$, sigue esta concepción tradicional de la mujer como trofeo a la que intentan conquistar un numeroso elenco de pretendientes (el boyero, el leñador, el bohemio, el señor, el cazador, el diablo). Finalmente, la hilandera escoge al estudiante que le ofrece «un corazoncito que tiembla de amor» (Fortún 2013: 138). Se puede percibir en la personalidad de la hilandera cierta transgresión de la tradición heteropatriarcal, puesto que es ella quien toma la decisión de elegir al pretendiente y lo hace movida por el amor, sin pretensiones materiales.

De la parte formal, como indica Cervera, «los ripios a que da lugar la versificación en pareados resultan graciosos en todo momento» (Cervera 1982: 164).

En la obra El manto bisiesto se pueden encontrar ciertos paralelismos con Luna lunera: ambas tienen un elevado número de personajes - diecinueve la primera y dieciocho la segunda - convirtiéndose en las dos más numerosas de Teatro para niños en lo que a personajes se refiere. Otro aspecto en común es el lugar: gran parte de la acción de las dos obras se lleva a cabo en palacio.

El manto bisiesto es una especie de proceso de Penélope a la inversa: la Reina, que tiene trescientos sesenta y cinco mantos, ofrece casar a su hijo con la que le teja un manto de un nuevo tejido para el día que sobra del año bisiesto. La moraleja es convencional y sigue el hilo de la mencionada anteriormente: vence la sencillez y el amor puro, representado por la figura de la pescadora que tejió el manto con el pelo de sus trenzas, frente al afán de ostentar de las princesas más ricas de diversos países del mundo. Como señala Cervera al referirse a esta obra, «aparte la exaltación de la persona humilde, muy en la línea paternalista al uso, hay una alusión de tipo humano interesante y es cuan-

\footnotetext{
${ }^{46}$ ABC (Madrid). (14/06/1936), p. 53. Recuperado de http://hemeroteca.abc.es/nav/Navigate.exe/hemeroteca/madrid/abc/1936/06/14/053.html y Cervera 1982: 164.
} 
do la reina rechaza un manto de perlas porque para hacerlo se habían perdido vidas humanas» (Cervera 1982: 165).

\section{Conclusiones}

Elena Fortún es, gracias a la serie narrativa Celia (1928-1987) y a Teatro para niños (1936), una de las autoras de Literatura Infantil más representativas de la literatura española de preguerra. Escritora de vocación tardía, no empieza a publicar hasta 1928. Su obra literaria obtuvo un rápido reconocimiento y gozó de una gran aceptación entre el público infantil, al que Fortún se dirigió con un lenguaje y gracia que rápidamente captó la atención de este.

Destacó como narradora pero también como autora teatral. Con su Teatro para niños, se apartó de la intención moralizante de la dramaturgia que mayormente había triunfado en la escena española para niños a lo largo del primer tercio del siglo XX. Su voluntad de renovar el género le impulsa a escribir piezas teatrales en las que predomina un lenguaje ágil y vivo, y en las que las canciones y los juegos verbales cobran una importancia trascendental.

Elena Fortún, junto a Magda Donato y Concha Méndez, forman el elenco de autoras de preguerra de teatro infantil que buscaron nuevas sendas en la escritura teatral, dejando atrás otros modos de escritura más tradicionales, representados por dramaturgas como Cristina Aguilá, Pilar Contreras, Micaela de Peñarranda, Matilde Ribot y Carolina de Soto, que otorgaban a sus obras un mensaje moralizante y adoctrinador en consonancia con los modelos de conducta positiva imperantes en los años 20 y 30 .

El análisis de las obras que conforman Teatro para niños desvela una de las intenciones primordiales de Elena Fortún al escribir sus piezas teatrales: llegar de la manera más directa posible al público infantil. Para llevar a cabo este propósito, se sirve de variados recursos, entre los que destaca el marcado tono humorístico e irónico con los que trata situaciones y personajes, a los que caracteriza particularmente; la mezcla de elementos tradicionales y modernos; así como la inclusión de elementos fantásticos en situaciones reales. Por último, en su afán de crear un teatro renovador y que haga reflexionar al niño, destacan las moralejas presentes en sus obras, mucho más complejas en su forma y contenido que las de la tradición más dogmática.

\section{BIBLIOGRAFÍA CITADA}

Aguilera Sastre, Juan (2011). «Las fundadoras del Lyceum Club femenino español», Brocar: Cuadernos de investigación histórica. 35, pp. 65-90.

Aznar Soler, Manuel (1993). Max Aub y la vanguardia teatral (Escritos sobre teatro, 1928 1938). Valencia: Universitat de Valencia. 
Branciforte, Laura María (2012). Ritmos contemporáneos. Género, politica y sociedad en los siglos XIX y XX. Madrid: Editorial: Dykinson.

Bravo-Guerrerira, María Elena y Fiona Maharg-Bravo (2003). «De niñas a mujeres: Elena Fortún como semilla de feminismo en la literatura infantil de la postguerra española», Hispania. 86 (2), pp. 201-208.

Caamaño Alegre, Beatriz (2007). «Cosas de niñas: la construcción de la feminidad en la serie infantil de Celia, de Elena Fortún», Analecta Malacitana. 23, pp. 33-59.

Capdevila-Argüelles, Nuria (2005). «Elena Fortún (1885-1952) y Celia. El Bildungsroman truncado de una escritora moderna», Lectora. 11, pp. 263-280.

Capdevila-Argüelles, Nuria (2014). «Introducción», en Nuria Capdevila-Argüelles y María Jesús Fraga, El camino es nuestro. Madrid: Fundación Banco Santander, pp. XIII-XXXIV.

Cervera, Juan (1982). Historia crítica del teatro español. Madrid: Editora Nacional.

Dorao, Marisol (1999). Los mil sueños de Elena Fortún. Cádiz: Servicio de Publicaciones de la Universidad de Cádiz.

Eiroa San Francisco, Matilde (2015). «El Lyceum Club: cultura, feminismo y política fuera de la aulas», en Josefina Cuesta Bustillo, Maria José Turrión García y Rosa María Merino (eds.), La residencia de señoritas y otras redes culturales femeninas. Salamanca - Madrid: Ediciones de la Universidad de Salamanca — Fundación José Ortega-Gregorio Marañón, pp. 197-226.

Fagoaga, Carmen (2002). «El Lyceum Club de Madrid, élite atente», en Daniéle Bussy Genevois, Les Espagnoles dans l'histoire. Une sociabilité démocratique (XIX-XX siecles). Saint-Denis: Presses Universitaires de Vincennes, pp. 145-67.

Fortún, Elena (2013). Teatro para niños. Sevilla: Espuela de plata.

Fraga, María Jesús (2013). Elena Fortún, periodista. Madrid: Editorial Pliegos.

Franco, Marie (2005). «Para que lean los niños: II República y promoción de la literatura infantil», en Jean Michel Desvois (ed.), Prensa, impresos, lectura en el mundo hispánico contemporáneo: homenaje a Jean-François Botrel. Bordeaux: Pilar, pp. 251-72.

García Padrino, Jaime (1986). «El mundo literario de Elena Fortún», en Jaime García Padrino y Carmen Bravo-Villasante, Elena Fortún (1886-1952). Madrid: IBBY, pp. 31-54.

García Padrino, Jaime (2001). Asi pasaron muchos años... En torno a la Literatura Infantil Española. Cuenca: Universidad de Castilla-La Mancha.

González Naranjo, Rocio (2015). «Ilustres tontas y locas: el Lyceum Club de Madrid, todo un ejemplo de solidaridad femenina», en Mercedes González de Sande, Daniele Cerrato y Eva María Moreno Lago (eds.), Locas: escritoras y personajes femeninos cuestionando las normas. Sevilla: Arcibel Editores, pp. 736-747.

González Santamera, Felicidad (2003). «El teatro femenino», en Fernando Doménech Rico y Emilio Peral Vega (eds.), Historia del teatro español. Del Siglo XVIII a la época actual. Madrid: Gredos, pp. 2502-2525.

Hurtado, Amparo (1999). «El Lyceum Club femenino (1926-1939», Boletín de la Institución Libre de Enseñanza. 36, pp. 23-36.

Mangini González, Shirley (2001). Las modernas de Madrid: las grandes intelectuales españolas de la vanguardia. Madrid: Península.

Mangini González, Shirley (2006). «El Lyceum Club de Madrid un refugio feminista en una capital hostil», Asparkia. 17, pp. 125-140.

Martens, Hanna Veerle Lut (2016). Tradición y censura en las traducciones de literatura infantil y juvenil en la cultura franquista: los cuentos de Perrault en español hasta 1975 (Tesis doctoral). Universidad de Extremadura, Cáceres.

Martín Gaite, Carmen (2004). Celia lo que dice. Madrid: Alianza Editorial.

Medina Padilla, Arturo (1987). Pinto Maraña. Valladolid: Miñon. 
Miró, Emilio (1992). «La contribución teatral de Concha Méndez», en Dru Dougherty y María Francisca Vílches de Frutos (eds.), El teatro en España entre la tradición y vanguardia. Madrid: CSIC, pp. 439-451.

Moreno Lago, Eva María. «La identidad de las exiliadas de Lyceum Club en sus escritos autobiográficos», en Pedro Luis Ladrón de Guevara Mellado, María Belén Hernández González y Zosi Zografidou (eds.), Marisa Madieri: escritoras del éxodo y del exilio. Murcia: Universidad, pp. 241-252.

Nieva de la Paz, Pilar (1993). Autoras dramáticas españolas entre 1918 y 1936 (Texto y representación). Madrid: CSIC.

Nieva de la Paz, Pilar (1993). «Las escritoras españolas y el teatro infantil de preguerra: Magda Donato, Elena Fortún y Concha Méndez», Revista de Literatura. LV, 101, pp. 113-128.

Otero, Luis (1999). La Sección Femenina: De cuando a la mujer española se le pedía ser hogareña, patriota, obediente, disciplinada, abnegada, diligente, religiosa, decidida, alegre, sufrida y leal. Madrid: Edaf.

Regueiro Salgado, Begoña (2015). «Imágenes de mujer moderna en la literatura infantil escrita por mujeres (1900-1939): Sofía Casanova, Carmen Conde y Magda Donato», en Elisabeth Delrue (eds.), La narrativa española (1916-1931): Entre historia cultural y especificidades narrativas. París: Indigp \& Côté-femmes éditions, pp. 115-133.

Sotomayor, María Victoria (2005). «Censura y libros para niños tras la Guerra Civil española», en Veljka Ruzicka et al. (eds.), Mundos en conflicto: representación de ideología, enfrentamientos sociales y guerras en la literatura infantil y juvenil. Vigo: Asociación Nacional en Investigación de Literatura Infantil y Juvenil, pp. 397-412.

Sotomayor, María Victoria (2013). «El universo infantil de Elena Fortún a escena», El kiosco teatral. 5. Accesible en: <http://www.aat.es/elkioscoteatral/leer-teatro/leer-teatro-5sumario/n-o-5-jugando-al-teatro-3-1-teatro-para-ninos-y-jovenes/> [ref. de 24/04/17]

Uría Ríos, Paloma (2000). «Celia en la Revolución (1943), de Elena Fortún», en Antonio Fernández Insuela (eds.), Sesenta años después. El exilio literario asturiano de 1939. Oviedo: Universidad, pp. 289-297.

Uría Ríos, Paloma (2004). «Las novelas de Elena Fortún», en En tiempos de Antoñita la Fantástica. Madrid: Foca Ediciones, pp. 29-68.

Vega, Elena de la (Febrero 1936). «El libro infantil: los últimos juguetes de papel y tinta», Gaceta del libro. III, 16, p. 6.

VV. AA. (1996). Autoras en la historia del Teatro Español (1500-1994). Volumen II. Madrid: Publicaciones de la Asociación de Directores de Escena de España.

VV. AA. (2008). Pequeña memoria recobrada: libros infantiles del exilio del 39. Madrid: Ministerio de Educación, Política Social y Deporte, Subdirección General de Información y Publicaciones.

Vilches de Frutos, María Francisca y Dru Dougherty (1997). La escena madrileña entre 1926 y 1931. Madrid: Editorial Fundamentos.

Fecha de recepción: 22 de agosto de 2016.

Fecha de aceptación: 6 de marzo de 2017. 